that of surface rock $(3 \cdot 3)$, then the radius of the sphere would be about $\mathbf{2} \cdot \mathbf{7 4}$ miles. Relevant factors, such as the atmospheric resistance and the control of direction, have been neglected. If they were taken into account, the initial mass would be still greater. On these calculations the rocket ship would be more than five miles in diameter, and would be as massive as Mount Everest.

\section{Mammals and Man}

WrTH the view of adding definiteness to the rather vague popular ideas of the class of mammals, the Zoology Department of the National Museum of Wales has set up a temporary series of exhibits for which a descriptive pamphlet, "Mammals and Man", has been written by the keeper of the Department, Colin Matheson (pp. 22. 3d.). The exhibits show representatives of the main groups of mammals, and indicate some of the ways in which mammals con. tribute to the welfare of humanity. Thus it is pointed out that of 3,500 known species of mammals, only about twenty have been thoroughly domesticated, and some of the breeds of the most familiar animals are illustrated among the exhibits. The economic products of the group are represented by wools of various kinds, by furs, particularly dressed furs made from rabbit skins, leather, many products of bones, food materials and so on. The arrangement follows the economic zoology which was a popular diversion of last century, but we miss references to modern developments such as the varied and most important uses of whale oil, the increasing resort to mammal products in biological therapy, and the importance assumed by mammals as reservoirs of disease organisms of man or domestic stock, as in the case of cattle disease in Africa, or as the carriers and communicators of disease, as in the case of the vampire bat. This exhibition, and all such special exhibitions, will do much to keep alive general interest in museum collections, which are always in danger of becoming static and unenterprising.

\section{Mounting Museum Specimens in Plastic}

ONE of the great handicaps in making attractive to the ordinary museum visitor specimens of the smaller organisms has been the need for mounting such in formaldehyde, alcohol, or other fluid, which almost invariably bleaches colour and makes necessary awkward methods of attachment. To a considerable extent that difficulty has been overcome by the use of an acrylic resin, 'Plexiglasis', the product of experiments conducted by Dr. Otto Rohm, of Philadelphia. Dr. Charles E. Sands, of the Bureau of Agricultural Chemistry and Engineering, has developed a method of embedding specimens in blocks of this material so that they resemble fossils preserved in amber, except that 'Plexiglass' is colourless and crystal-clear, clearer it is said than the finest glass, and will retain its transparency permanently. Specimens before embedding must be dehydrated in air or with alcohol or dioxan, and the setting is done in vacuum to prevent the inclusion of air-bubbles while the mountant is changing from semi-fluid to the solid state. A collection of miscellaneous specimens mounted in this way was on view at the New York World's Fair, and is permanently shown in the Franklin Institute in Philadelphia.

\section{Fertility Rules in Fruit Planting}

THE John Innes Horticultural Institution has produced a very useful leaflet (No. 4) with the above title, which sets out clearly the rulès for interplanting fruit trees to ensure effective pollination. Based on many years of research to test the success of crosses between varieties of cherries, plums, pears and apples, this leaflet will be an invaluable guide to growers in the planning of new orchards and in the improvement in fertility of existing trees. It is estimated that the value of the total fruit crop of Great Britain could be increased 10-20 per cent by correct interplanting. In some existing orchards containing large blocks of trees of a single variety, much could be done to increase the crop by top. grafting a proportion of the trees with suitable pollinators. Brief reference is made in the leaflet to the causes of unfruitfulness, and exhaustive lists are provided to show which varieties are self-compatible and which varieties will ensure effective crosspollination. Attention is directed to the reduced population of wild bees in many orchard districts and the necessity for keeping hive-bees in correctly interplanted orchards.

\section{Feeding Value of Silage}

Farmers must be able to judge the feeding value of their silage, and to meet this need the Ministry of Agriculture has issued Bulletin No. 50 in the "Grow. more" series. High-quality silage is a cake substitute and can only be obtained from the right crop, cut at the right time and properly ensiled. The colour, smell, texture and dry-matter content of material in this category are described, and recommendations given as to the rate at which it should be fed. If any of the requisite conditions is not fulfilled, the silage can only be used to réplace hay, roots, or oat straw. The value of such material varies considerably according to the type of crop from which it is made, or to the conditions during ensiling, but suggestions are given as to the rationing of several of the lowprotein silages. For the less experienced farmer, a useful table is included, in which the common faults in silage, their cause and the appropriate remedy are described, and if still further information is desired, application can be made to the county agricultural organiżer.

\section{A New Pavlov Manuscript}

Mr. M. KRUTIKov, who is working at the archives of the Academy of Sciences of the U.S.S.R., has discovered the manuscript of a hitherto unknown work by the Russian physiologist, the late Prof. I. P. Pavlov. The work, which had been submitted for a competition for a prize of the Academy, is entitled "The Centrifugal Nerves of the Heart", and it is dated 1885 ; it consists of 19 pages. It seems that when the manuscript reached the Academy 